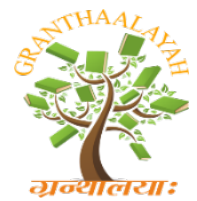

\author{
INTERNATIONAL JOURNAL OF RESEARCH - \\ GRANTHAALAYAH \\ A knowledge Repository
}

Science

\title{
COMPARATIVE ANALYSIS OF THE BENEFITS AND DIFFICULTIES OF OBSTETRIC PSYCHOPROPHYLAXIS, IN PREGNANT WOMEN OF THE HEALTH CENTERS OF CUMANDÁ AND CERECITA - ECUADOR
}

\author{
Obsta Vicky Narea Morales MSc ${ }^{1}$, Dr. Jorge Daher Nader PhD ${ }^{1}$, Obsta. Katherine \\ Rodríguez $^{1}$, Obsta. Cynthia Carolina Armijo Baño ${ }^{1}$, Obsta Gabriel Jiménez ${ }^{1}$ \\ ${ }^{1}$ Teachers of The Career of Obstetrics of The Faculty of Medical Sciences of The University of \\ Guayaquil-Ecuador
}

\begin{abstract}
The woman who is in a state of gestation tends to create fears implanted by rumors of society about labor, the main fear is the pain caused by labor. Only through a comprehensive, adequate, timely preparation will favorable results be achieved; by obstetric psychoprophylaxis. The research was carried out in two Health Centers in different regions of Ecuador. The Cerecita health center is located in the Cerecita enclosure, Guayaquil canton, Guayas province and the Cumandá health center which is located in the Cumandá canton within the Chimborazo province. This research work corresponds to a descriptive, analytical, non-experimental, cross-sectional study, with a correlational design. The sample consists of 198 pregnant women from the health centers of Cerecita (94) and Cumandá (104) Ecuador, nulliparous and multiparous who attended sessions of Obstetric Psychoprophylaxis that met the inclusion and exclusion criteria. The results obtained were: in the age range in which the pregnant women were from the study carried out was between 14 and 19 years with a total of 95 patients, the attitude to practice psychoprophylaxis (PPO) with 102 patients performed Between 3 and 4 sessions, in the hours of labor the largest number with a total of 98 pregnant women were between 5 to 7 hours in this period, while 100 had a low pain threshold. Of the study group 159 pregnant women were eutocic births, the pregnant women of the Cumandá health center presented difficulties in attending the obstetric psychoprophylaxis sessions.
\end{abstract}

Keywords: Obstetric Psychoprophylaxis; Labor; Benefits.

Cite This Article: Obsta Vicky Narea Morales MSc, Dr. Jorge Daher Nader PHD, Obsta. Katherine Rodríguez, Obsta. Cinthya Baño, and Obsta Gabriel Jiménez. (2020). "COMPARATIVE ANALYSIS OF THE BENEFITS AND DIFFICULTIES OF OBSTETRIC PSYCHOPROPHYLAXIS, IN PREGNANT WOMEN OF THE HEALTH CENTERS OF CUMANDÁ AND CERECITA - ECUADOR." International Journal of Research Granthaalayah, 8(3), 297-303. https://doi.org/10.5281/zenodo.3737860. 


\section{Introduction}

Obstetric psychoprophylaxis is the set of techniques that are used as an instrument of prevention, through training in order to obtain positive results in care during pregnancy and childbirth, it is carried out in sessions scheduled by the obstetrician, explaining to the pregnant women about the benefits in the evolution of pregnancy and also to achieve a better collaboration during the program and in labor and delivery, preventing these periods from being prolonged and that at the time of the newborn's head exit at outside the maternal cavity does not cause perineal tears and is not long lasting. (RAMBAY, 2019)

With this practice, the patient is helped to clear up doubts and myths regarding the evolution of pregnancy and childbirth, with the exercises the pelvic floor muscles will be helped to have greater elasticity, thus reducing unnecessary episiotomies and caesarean sections, due to prolonged dilation. and lack of collaboration of the pregnant woman. Despite being a practice that has existed since ancient times, in our country it has been carried out more frequently a decade ago before the urgent need to improve maternal and fetal health. According to the clinical practical guide to cesarean delivery care of the Ministry of Public Health of Ecuador, in 2014 the rate of caesarean section was $41.2 \%$, when the recommendations of the World Health Organization indicate that they should not be exceed $15 \%$, for this reason the importance of vaginal delivery or normal delivery, its benefits and advantages is imparted in the country. (Ministry of Public Health, 2016) In 2014 the technical norm of obstetric psychoprophylaxis and prenatal stimulation of the Ministry of Public Health was implemented in Ecuador. Its general objective is to strengthen the Health System that guides the actions that must be carried out in the Health Units to provide obstetric psychoprophylaxis to pregnant women, as part of their comprehensive care, with a family, community and intercultural approach, guaranteeing quality care and improving health indicators, contributing to the reduction of maternal and perinatal morbidity and mortality in Ecuador. (MSP, 2014). The rationale for this research is to identify the benefits of obstetric psychoprophylaxis in pregnant women and newborns; Identifying difficulties and reasons for desertion, abandonment of obstetric psychoprophylaxis among pregnant women in the community of Cumandá and Cerecita to propose alternative solutions is what motivated me to carry out the present study, the pregnant woman needs to face her delivery in the best possible conditions with information that makes you aware of your leading role in the birth of your child, and enjoy the benefits of psycho-prophylactic preparation for both the mother and the unborn child, it is important to carry out the present research work of "Comparative analysis of the benefits and difficulties of obstetric psychoprophylaxis in pregnant women of the Health Centers of Cumandá and Cerecita - Ecuador 2019. It will allow me to make a comparative analysis of the reality of pregnant women who perform obstetric psychoprophylaxis in Cumandá - Cerecita.

\section{Materials and Methods}

It is a non-experimental cross-sectional study. It is Inductive - Analytical, Correlational because the study variables are related to reach general and significant conclusions. The sample will consist of a total of 198 pregnant women from the Cerecita health center and the Cumandá health center, in order to carry out a correlational study, Cerecita 94 patients and Cumandá 104 patients, who attended obstetric psychoprophylaxis sessions that met the inclusion and exclusion criteria. In the 
inclusion criteria, pregnant women whose birth is eutocic, single fetus, all presentations, pregnant women who attended obstetric psychoprophylaxis sessions are included. In the exclusion criteria, pregnant women whose delivery will be caesarean section, multiple pregnancy, pregnant women with high-risk pregnancy are excluded.

\section{Results}

1) Correlation of benefit variables by the practice of Obstetric Psychoprophylaxis.

Table 1: Benefit Psychoprophyilaxis Obstétric.

\begin{tabular}{|l|lr|rc|}
\hline Mother variables & \multicolumn{2}{|c|}{$\begin{array}{c}\text { SESSIONS PPO } \\
\text { Cumandá (104) }\end{array}$} & \multicolumn{2}{c|}{$\begin{array}{c}\text { SESSIONS PPO } \\
\text { Cerecita (94) }\end{array}$} \\
& N & N & \% \\
\hline Complete dilation up to 6 Hours & 99 & $95 \%$ & 80 & $85 \%$ \\
\hline No use of medications & 90 & $86 \%$ & 89 & $94 \%$ \\
\hline Expulsion less than 25' & 100 & $96 \%$ & 90 & $95 \%$ \\
\hline Eutocic birth & 98 & $94 \%$ & 89 & $94 \%$ \\
\hline Clear amniotic liquid & 100 & $96 \%$ & 90 & $95 \%$ \\
\hline
\end{tabular}

Source: Gestantes de Cumandá and Cerecita - Ecuador 2019.

Analysis and Interpretation- In table number one we can see a significant positive correlation in the Attitude variable for the practice of Obstetric Psychoprophylaxis with the Pain threshold variable, and inversely proportional to the variables Number of deeds and Hours of labor, so it interprets that the better It is the attitude that pregnant women have in attending PPO sessions, the better their pain threshold will be, as well as the greater the number of pregnancies, the labor will be much faster, that is, the hours of labor will be reduced to those that will be submitted.

\section{Results}

2) Correlation of difficulties variables by the practice of Obstetric Psychoprophylaxis.

Table 2: Difficulties variables by the practice of Obstetric Psychoprophylaxis.

\begin{tabular}{|l|lr|rr|}
\hline New born variable & \multicolumn{2}{|c|}{ PPO } & \multicolumn{2}{c|}{ PPO } \\
& Cumandá (104) & \multicolumn{2}{c|}{$\begin{array}{c}\text { Cerecita (94) } \\
\text { \% }\end{array}$} \\
\hline APGAR 1' $>8$ & 100 & $95.7 \%$ & 89 & $94.6 \%$ \\
\hline APGAR 5' $>8$ & 103 & $99,03 \%$ & 89 & $94.6 \%$ \\
\hline APNEA AT BIRTH & 4 & $3.84 \%$ & 3 & $3.19 \%$ \\
\hline $\begin{array}{l}\text { EXPULSIVE < 25' EN } \\
\text { FETO }>3500 \text { gramos. }\end{array}$ & 18 & $17,30 \%$ & 3 & $3.19 \%$ \\
\hline
\end{tabular}

Residence (place where you live: coast or mountains). Attitude for practice (number of attending PPO sessions). Residence area (urban, rural and urban marginal)

Source: Gestantes de Cumandá and Cerecita - Ecuador 2019. 
Analysis and Interpretation- Table two shows a significant positive correlation of the variable difficulties to perform the PPO with residence, and negatively or inversely proportional to the occupation variable, so it is interpreted that patients who are in the Sierra region, present greater difficulty to PPO assistance and the higher the occupation, the less assistance. Regarding the residence variable compared to the attitude and collaboration variables and with the variable residence zone, an inversely proportional significance was found, interpreting that the further your zone of residence, the more negative your attitude to the practice of PPO will be

\section{Results}

3) Correlation between pain threshold variable and attitude for the practice of obstetric psychoprophylaxis.

Table 3: Threshold relation of pain and attitude for the practice of PPO

\begin{tabular}{|l|lr|rc|}
\hline DIFFICULTI PPO & \multicolumn{2}{|c|}{$\begin{array}{c}\text { SESSIONS DE PPO } \\
\text { Cumandá 104 }\end{array}$} & $\begin{array}{c}\text { SESSIONSDE PPO } \\
\text { Cerecita 94 }\end{array}$ \\
\hline No Difficulties & 64 & $61 \%$ & 85 & $90 \%$ \\
\hline Hour Inadequate & 10 & $9,6 \%$ & 7 & $7,44 \%$ \\
\hline Inadequate ambiences & 12 & $11,53 \%$ & 0 & $0.00 \%$ \\
\hline Lack of comfort & 14 & $13,56 \%$ & 0 & $0.00 \%$ \\
\hline $\begin{array}{l}\text { Lack of commitment on the part } \\
\text { of the couple. }\end{array}$ & 4 & $3.84 \%$ & 2 & $2,12 \%$ \\
\hline
\end{tabular}

Source: Gestantes de Cumandá and Cerecita - Ecuador 2019.

Analysis and Interpretation- In the relationship contingency table of the Attitude variable for the practice of Obstetric Psychoprophylaxis (determined by sessions attended to the PPO), with the variable Threshold of pain, 100 patients studied presented a low pain threshold, having 76 of them an attitude classified as bad for the practice of PPO (1 - 2 session); unlike 20 patients who had a high pain threshold and of which only 9 of them maintained a better attitude for the practice of PPO.

\section{Results}

4) Correlation between the Occupation and Residence variables.

Table 4: Relationship between occupation and residence.

\begin{tabular}{|c|c|c|c|c|}
\hline \multicolumn{5}{|c|}{ Occupation * Cross tabulation residence } \\
\hline & & Cumandá & Cerecita & \\
\hline \multirow{4}{*}{ Occupation } & Housewife & 58 & 60 & 118 \\
\hline & employee & 13 & 14 & 27 \\
\hline & Estudent & 15 & 14 & 29 \\
\hline & Merchant & 18 & 6 & 24 \\
\hline \multicolumn{2}{|l|}{ Total } & 104 & 94 & 198 \\
\hline
\end{tabular}

Source: Gestantes de Cumandá and Cerecita - Ecuador 2019. 
Analysis and Interpretation-In table number four, the correlation of the residence variable with the occupation variable, it is highlighted that 108 study patients are engaged in household chores (housewives), of which 60 reside in the Cerecita enclosure; compared to 24 who are engaged in commerce (merchant) and 18 patients are from the Cumandá cantón.

\section{Discussion}

Most of the patients in the Sierra region presented difficulty in attending psychoprophylaxis sessions regardless of the risks they were subjected to at the time of labor, due to the poor interest they give and having an occupation.

The pain threshold that represents one of the greatest fears in women, was presented in an appropriate manner in those who continuously attended the obstetric psychoprophylaxis sessions stipulated in the PPO technical standard; obtaining effect in labor, making these hours shorter and the pain threshold higher in relation to pregnant women who do not attend the full sessions.

The most relevant difficulty in the pregnant women of this study is reflected in the schedules in which the practice of obstetric psychoprophylaxis is carried out, because many of them present work at home, another of the difficulties they presented was that Cohabitants did not allow them to attend PPO sessions. Likewise, the environment in which it is developed was not adequate for the aforementioned practice, as stipulated in the PPO technical standard.

\section{Conclusions}

Psychoprophylaxis, despite being an important technique to improve maternal fetal well-being at the time of labor, due to ignorance of its advantages, is not of much interest to patients. This investigation concludes the following:

- It is concluded that in this investigation the benefits and difficulties of pregnant women in both the coastal region (Cerecita) and the Sierra region (Cumandá) despite not having any type of occupation and impediment to attend psychoprophylaxis sessions, there was no interest in multiparous pregnant women, there was greater interest in nulliparous pregnant women, because of the fear of the unknown, they came to the realization of these practices.

- The analysis of acceptance of the PPO sessions, it was expressed that the highest percentage of patients who attended the psychoprophylaxis sessions were Cerecita pregnant women, who were participatory and collaborative.

- The patients who attended the scheduled obstetric psychoprophylaxis sessions are those who presented the greatest benefit at the time of their labor because their tolerance for pain was greater and their labor hours were much shorter.

- The main difficulty in Cumandá, which was presented in this investigation was the inaccessibility to locate pregnant women in their homes, because being Cumandá a region of the mountains of Ecuador and being in the foothills of the Andes mountain range, that made access to the plots where patients live difficult.

- The main difficulty in Cerecita was the remoteness of the homes of pregnant women, the dispersed and difficult access of their homes because Cerecita is a rural parish in the province of Guayas. 
Recommendations Being of great benefit to the mother and child binomial, Obstetric Psychoprophylaxis recommends the following: 1.-Provide through educational talks to patients, the benefits offered by these practices at the time of labor and the benefit that their babies would have. 2.- Provide facilities in practice schedules considering the socio - demographic characteristics of each patient and improve the environment in which they develop to achieve the warmth of the moment. 3.- Raise awareness among pregnant women in the health establishment of cerecita, and Cumandá so that $100 \%$ comply with the completion of six or more sessions of psychoprophylaxis. 4.- Establish adequate schedules, improve comfort and that there is adequate physical space in the health center Cerecita and Cumandá, so that pregnant women can attend. 5.Carry out a multidisciplinary work throughout the gestational process in order to improve physical and psychological aspects in the health of the mother and the newborn. In the health of the mother and the newborn. 6.- It is advisable to take into account that obstetric psychoprophylaxis should begin in the second trimester, at this stage the joints are more flexible and the discomforts, such as vomiting, nausea are decreasing, more so the mother becomes aware of her condition looking for the welfare of his future son and his own.

\section{References}

[1] Aguilar Cordero, M., Vieite Ravelo, M., Padilla Lopez, C., Mur Villar, N., Gomez García, C., \& Rizo Baeza, M. (2012). Perinatal results at the time of delivery of women who received the prenatal stimulation program, Hospital. Hospital Nutrition, 2102-2108.

[2] National Constituent Assembly of Ecuador. (2008). Constitution of the Republic of Ecuador. Obtained from www.oas.org

[3] Atencia Jara, Y., \& Carhuapoma Pineda, M. (2018). UNASAM Institutional Repository. Obtained from www.repositorio.unasam.edu.pe

[4] Campos de Aldana, M. (2010). Pain management during labor during pregnancy in a health center. Take care of yourself: Research magazine, 43. Obtained from Care: Research magazine.

[5] Carhuapoma Hilario, A. (2017). Universidad Nacional Huancavelica. Obtenido de www.repositorio.unh.edu.pe

[6] García Paredes, V. (2017). Digital Institutional Repository. Obtained from www.repositorio.unapiquitos.edu.pe.

[7] Gomez Medina, E. (2016). Factors associated with the end of the educational sessions of obstetric psychoprophylaxis in teenage pregnant women. Obtained from the National University of San Marcos: www.cybertesis.unmsm.edu.pe

[8] Martínez Galeano, J. (2012). Impact of the Maternal Education Program on the Mother and the Newborn. Retrieved from www.-hera.ugr.es.adrastea.ugr.es.

[9] Méndez García Salas, M. (August 2015). Psychoprophylaxis and Complications in Labor (Thesis). Obtained from www.recursosbiblio.url.edu.g

[10] Ministry of Public Health. (2014). Technical standards of Obstetric Psychoprophylaxis and perinatal stimulation. Recovered 2018

[11] Ministry of Public Health. (08 of 2016). Clinical practice guide to cesarean delivery care. Retrieved on 12 of 2018

[12] NAREA. (2017). Benefits and difficulties of obstetric psychoprophylaxis in pregnant women of the cerecita health center, Guayas -Ecuador. Cidepro.

[13] RAMBAY (May 2019). Comparative analysis of the benefits and difficulties of Obstetric Psychoprophylaxis between the Cerecita and Cumanda health centers 2019. Guayaquil, Ecuador.

[14] Ramírez Mattos, J. (2017). San Pedro University. Obtained from www.repositorio.usanpedro.edu.pe 
[15] Reyes, A. (2014). Factors associated with attrition of the educational sessions of obstetric psychoprophylaxis in primigests attended at the Maternal Perinatal Institute. Recovered 2018

[16] Rivera Orellana, K. (2016). Causes for dropping out of the Obstetric Psychoprophylaxis program in pregnant women at the Rezola de Cañete Hospital. Obtained from the University of San Martin de Porres: www.repositorioacademico.usmp.edu.pe.

[17] Rubio Peralta, F. (2018). Norbert Wiener University. Obtained from Emergency Obstetric Psychoprophylaxis in labor of primigesta without prenatal control: www.repositorio.uwiener.edu.pe

[18] Saavedra Espinoza, W., \& Yauris Ocrospoma, C. (July-December 2017). Norbet Wiener University. Obtained from a comparative study of maternal and perinatal benefits during the labor of patients who attended and did not attend the PPO program of the Hipólito Unanue National Hospital: www.repositorio.uwiener.edu.pe

[19] Seguí, V. E. (Septiembre de 2013). Universidad Nacional de la Plata. Obtenido de www.sedici.unlp.edu.ar.

[20] Yábar Peña, M. (June 2014). Scielo Peru. Obtained from http://www.scielo.org.pe

*Corresponding author.

E-mail address: vicky.naream@ug.edu.ec/Jorge.dahem@ug.edu.ec/Katherine.rodriguezb@ug.edu.ed Gabriel Jimenezv@ug.edu.ed/ cynthiak-rolina95@ hotmail.com 